\title{
10
}

\section{Virtue Ethics and the Demands of Social Morality}

\author{
BRADFORD COKELET
}

\section{THE CHALLENGE}

According to virtue ethicists who are inspired by Anscombe (1958) and Williams (1985), we should abandon the core modern moral idea: that persons are subject to distinctively moral obligations or duties, which they owe to one another in virtue of their inherent value or dignity. Because this idea is philosophically and practically problematic, virtue ethicists argue, we should try to find a way to leave it behind, both in theory and in practice. This resolute rejection of what we can call legalistic deontic morality ${ }^{1}$ puts virtue ethicists deeply at odds with contemporary neoKantians, and Kantians typically respond by arguing (i) that they can put legalistic moral thought and practice on a respectable philosophic footing and (ii) that giving up on that modern morality would either be irrational or lead to devastating practical consequences. They hold, in other words, that virtue ethical theories are inadequately motivated and that they have practically problematic, revisionary implications.

In this chapter I focus on the objection that, while virtue ethicists can provide us with attractive or admirable individual ideals, they cannot do justice to the demands of social morality. ${ }^{2}$ Specifically, the

\footnotetext{
1 Doing without legalistic deontic morality does not entail doing without all concepts one might think of as deontic. For example, radical virtue ethicists may encourage us to continue using concepts such as ought, must, should, right. Moreover some virtue ethicists give accounts of right action that do not involve directed moral obligations or duties. My focus here will be on the specific, anti-Kantian proposal that we refrain from positing universal, directed moral obligations or moral duties that are grounded in the dignity of persons (or, understood as Scanlon suggests, the special value of human life). Later, I will say more about how moral duties so understood contrast with the virtue ethical duties posited by Crisp (2014) and Annas (this volume).

2 As this suggests, my thinking about the objection is indebted to Strawson (1961).
} 
worry is that because they reject the idea of directed ${ }^{3}$ moral obligations, rooted in the value or dignity of persons, virtue ethical theories cannot account for the second-personal dimensions of social morality; they cannot account for the forms of interpersonal accountability that are characteristic of most ordinary human relationships or the fact that good moral motivation involves apt responsiveness to the expectations to which people in such relationships can rightly hold each other.

Consider an example: we should avoid carelessly harming our friends both because it will detract from their welfare and because they can rightly blame us for our lack of concern for their welfare. Now a virtue ethicist may well hold that the friend's lack of concern is a manifestation of vice (or "baseness") and that this provides a reason, above and beyond the prospective harm to the friend, to refrain from acting; but it is hard to see how those claims will ground an answer to the Kantians. Virtue and vice are standardly taken to be features that warrant admiration or disapproval, but those forms of reaction are not like the reactive attitudes that are characteristic of social morality (blame, guilt, indignation, etc.), and it is not clear how facts about the virtue or vice an agent manifests can determine whether or not she has lived up to the legitimate expectations of those with whom she interacts. Put generally, the worry is that the demands of social morality involve, and can only be vindicated by appeal to, expectation-grounding normative facts, such as facts that we owe certain things to others or that we would do wrong by others if we acted in certain ways, and since none of the normative concepts of which virtue ethicists make use (e.g. eudaimonia, virtue, nobility) are expectation-grounding, they will be unable to provide an adequate account of moral motivation, i.e. one that captures the fact that good motivation involves responsiveness to the demands of social morality.

This argument, which has been most fully and forcefully developed by Darwall (2009), is interesting for several reasons. First, it supports the Kantian view that virtue ethics is a wildly revisionary research program and does not constitute a viable alternative to deontology. Second, to rebuff the argument, virtue ethicists need to show that they can provide accounts of social morality without deploying deontic moral

\footnotetext{
3 A directed obligation or duty is one you have to another person.
} 
concepts and to explore how such accounts would fit into their larger theories. Finally, third, by outlining a virtue ethical account of social morality and rebuffing Darwall's neo-Kantian doubts about its conceptual coherence, we will be able to better characterize some of the core issues that divide Kantians and virtue ethicists. My hope is that this will set up a more productive debate about the comparative merits of virtue ethical and Kantian moral theories.

To begin, it will help to distinguish the argument from social morality, which I focus on here, from two similar objections that defenders of deontic morality lodge against virtue ethics. These are the categorical force and egoism objections. All three objections can be understood as specifications of the claim that while virtue ethical thinking may provide us with attractive individual ideals, it cannot do justice to the demands of social morality. The categorical force objection comes into view if we focus on the contrast between what is attractive and what is demanded. Roughly put, the objection is that while virtue ethical views can help us understand and justify claims about which activities and character traits are desirable, attractive, or admirable, they do not have the resources to ground ordinary (or theoretical but true) assumptions about what it is imperative-or perhaps "categorically" imperative-for us to do. This objection has a long history, ${ }^{4}$ but deontologists have had trouble getting it to stick. In short, the concept of being imperative is indeterminate and deontologists have so far failed to provide a specification of it that does the work they want it to do, i.e. to underwrite the claim that virtue ethical views cannot ground ordinary assumptions about what it is imperative for us to do. ${ }^{5}$

The egoism objection can also be thought of as a way of specifying the charge that, while virtue ethical thinking may provide us with attractive individual ideals, it cannot account for the demands of social morality; it comes into view when we turn our attention to the contrast between individual ideals and social morality. The basic

\footnotetext{
${ }^{4}$ See Larmore (1990) for discussion of this contrast and the way it shows up in Kant and Sidgwick.

5 To get a sense of how Aristotelian and Humean virtue ethicists can accommodate most ordinary assumptions about what it is ethically or morally imperative to do, see McDowell (1978), Stohr (2003), and Wiggins (1991). Foot (1972) can be read as arguing there is no intelligible specification that can ground the deontological attack.
} 
thought in this case is that virtue ethical views are problematically self-focused because they would answer all questions about what we ought to do, or how we should live, by appeal to facts about what would make our lives go better or worse and about what would make us or our actions admirable or deplorable. In response, virtue ethicists have plausibly insisted, first, that virtuous agents need not always be motivated by thoughts about their own virtue or how their actions would contribute to their flourishing, and, second, that being virtuous involves caring about others (or the common good ${ }^{6}$ ) for their (its) own sake. These points, and the additional one that virtue is a constituent of flourishing, not an instrumental means to it, may not refute all versions of egoism objection, ${ }^{7}$ but they do show that virtue ethical theories are not egoistic in the most straightforward and problematic senses.

This brings us to the third way of specifying the claim that while virtue ethical thinking may provide us with attractive individual ideals, it cannot do justice to the demands of social morality. The third version - the social morality objection proper-rests on doubts about whether virtue ethical thinking can accommodate the specific type of other-directed concern or motivation that is characteristic of ordinary human relationships. To accommodate social morality, a theory must accommodate the fact that we are ethically or morally answerable to others for the ways in which we treat them and that being a good ethical person involves being responsive to others' legitimate ethical expectations. And while virtue ethicists may well be able to account for the fact that a well motivated person cares about others and the common good for their own sake, that does not show that they can account for the moral significance of warranted social expectations and of our being answerable for living up to them or not.

\footnotetext{
${ }^{6}$ Irwin (1992) discusses the Aristotelian idea that acting for the sake of the noble ( $t a$ kalon) can involve acting for the common good, and critically considers the way the British Idealists appropriated that idea.

${ }^{7}$ For a recent restatement of the egoism objection see Hurka (2012); to get a sense of popular neo-Aristotleian responses see Toner (2006) and Annas (2008); and for a critical overview of the subsidiary debate about whether virtue ethics is problematically self-effacing see Pettigrove (2011).
} 


\section{DEVELOPING THE OBJECTION AND FINDING A SOLUTION}

Now that we have distinguished the social morality objection from some close cousins, we are ready to step back and develop it more systematically. To do so, it will help to focus in on Kantian legalistic theories and Aristotelian virtue ethical ones. Specifically, it will help to note some general differences that divide neo-Kantian and neo-Aristotelian accounts of moral motivation, understood as their accounts of the distinctive modes of deliberation, choice, and agency that are manifest in a morally well-motivated person. For our purposes, it makes sense to focus on three things any adequate account of moral motivation must do. ${ }^{8}$ First, it should identify and characterize the reasons or evaluative facts (or properties, or what have you) to which well-motivated agents are responsive. Second, it should identify the forms of responsiveness to these facts that constitute defective, good, and excellent moral motivation. These first two parts provide the core account of moral motivation. In addition to that core account, a theory of moral motivation should also tackle various questions related to the importance of being well motivated-for example, by giving accounts of moral responsibility, improvement, and morality's rational authority.

With these topics in mind, let us consider the typical Kantian core motivational account: it represents moral motivation as a form of sound, rational willing that reflects the agent's apt responsiveness to legalistic moral facts. This account has four component parts that it will be helpful to distinguish. First, following Kant, it involves positing the existence of distinctively moral facts that differ in normative character from teleological (good-based) ones..$^{10}$ Second, it involves thinking that the distinctive normative character of moral reasons is best understood in legalistic deontic terms-roughly speaking, we are morally obligated to treat persons in some ways and not others, they can validly expect that we will live up to these obligations, and they can hold us accountable if we fall short of them. Third, Kantians typically hold that

\footnotetext{
${ }^{8}$ My focus on moral motivation and my way of thinking about it are inspired by Scanlon (1982).

9 Additional topics that need to be addressed include questions about how to best explain moral motivation when it occurs, about the practices and institutions that can best generate or support moral motivation, and about why we should aspire to be morally motivated.

${ }^{10}$ See Kant 1997: 5: 57-66. In this section I read Kant as distinguishing moral worth from personal welfare, not impersonal absolute goodness from personal welfare.
} 
our moral obligations to one another are grounded in facts about the "intrinsic" and "unconditional" dignity or value of persons, rational agency, or human life, ${ }^{11}$ and they think that moral motivation involves respecting the dignity of all persons. Finally, Kantians tend to hold that we can recognize and fulfill our moral obligations to others just by willing well, where "willing" encompasses all that we can do by exercising the basic free and rational powers we share with all other (normal, mature) persons.

Next, consider Kantian views of responsibility. Accounts vary, of course, but Kantians typically aim to justify reactive attitudes such as resentment and guilt and to do so while embracing some sort of "obligation implies can" principle. Roughly, they hold that people are only responsible and accountable for failures of motivation that they could have avoided by willing differently. Kantians don't think this unduly restricts the scope of moral obligation, however, because they also think that normal mature humans can grasp and live up to the obligations that they must in order to respect the universal, inherent dignity of persons; they think we can perfectly respect the dignity of persons just by exercising our basic powers of free rational agency.

With this sketch of Kantian accounts of moral motivation in mind, we now turn to the very different Aristotelian accounts. Like other virtue ethicists, Aristotelians aim to develop an account of moral motivation that does not posit directed moral obligations which are rooted in the dignity of persons, and they tend to picture good motivation as a manifestation of good dispositional character and practical wisdom. This character and wisdom are characterized, at the theoretical level, with the use of virtue terms (courage, kindness, etc.) and the ethically appropriate reasons, for which the well motivated act, are identified as the ones to which the virtues (or virtue) make(s) one responsive. ${ }^{12}$ In

\footnotetext{
11 This does not, of course, preclude a constructivist account of the relevant evaluative facts or their normative force.

12 Aristotelians often deny that the relevant reasons are metaphysically or epistemically reducible to facts about virtuous character, activity, or agency, or vice versa; many follow McDowell and Wiggins in accepting "benevolently circular" response dependence views. For discussion of the meta-ethical issues surrounding this view see e.g. LeBar (2005).
} 
addition, Aristotelians often identify the virtues as the traits or intelligent dispositions that make one admirable (noble), a good member of the kind human, and that enable one to flourish or live well.

Before saying more, it might help to pause and say something about how Aristotelian uses of deontic concepts such as right, should, and duty differ from the legalistic deontic moral ones I am claiming they reject. Earlier, I introduced the phrase "legalistic deontic morality" to refer to views or practices that make use of the modern moral idea that people have moral obligations to each other and that these obligations are rooted in the inherent dignity of persons, so my claim is that Aristotelians reject this idea. This does not rule out, however, making claims about what it is morally right to do. This might, for example, be a way of expressing the belief that some ethical or moral consideration provides the person with sufficient reason to act. Similarly, the claim that someone has a moral duty to act might just express a belief that some moral consideration provides the person with compelling reason to act. The key point is that virtue ethicists may use concepts of moral duty or morally right action so understood, without committing themselves to either the existence of directed duties or obligations (owed to some specific people) or the idea that the relevant duties are grounded in the dignity of persons. Crisp (2014) and Annas (this volume), for example, have recently sketched virtue ethical views that incorporate the existence of duties, but neither account explains the existence of directed duties-duties that we owe to other persons-or appeals to the dignity of persons. On Crisp's view, we are duty bound to perform virtuous acts but there is no suggestion that duties are generally owed to others, while on Annas' view, duties are institutionally defined and not generally directed at specific other people. ${ }^{13}$

With these points in mind, we can now resume our characterization of Aristotelian accounts of moral motivation. Like Kantians, Aristotelians posit distinctively moral or ethical facts in order to explicate moral motivation-they posit reasons that are grounded in facts about virtue or vice and that are not reducible to teleological

${ }^{13}$ In n. 23, I say more about why I don't think Annas (this volume) shows us how to handle the social morality objection to virtue ethics. 
reasons (ones grounded in facts about welfare or good or bad states of affairs)—but, as just explained, they refuse to characterize these moral facts in legalistic deontic terms. Moreover, contemporary Aristotelians tend to shy away from the idea that moral motivation involves substantive, intentional responsiveness to the "aretaic" facts and prefer, instead, to picture this responsiveness as structuring the agent's deliberations in an indirect way. ${ }^{14}$ Most neo-Aristotelians reject, for example, the thought that an ideally virtuous agent will treat others well for the reason that doing so is part of living well or flourishing, or because it is the virtuous or noble thing to do. Insofar as they aim to accommodate the Kantian view that moral motivation involves acting on principle or doing the right thing because it is right, they are likely to follow Hursthouse's lead and deflate these to broadly externalist claims about the virtuous reliably and characteristically acting for the right ethical reasons-reasons that are conceptually linked with aretaic facts, but only at the theoretical level. ${ }^{15}$

When we turn to Aristotelian accounts of responsibility, it is useful to highlight the fact that Aristotelian moral motivation is a manifestation of a type of good dispositional character and practical wisdom that not all human beings possess. Aristotelians do tend to favor broadly cognitivist accounts of virtuous agency and are prone to identifying virtue with sound practical reasoning or practical knowledge, but they nonetheless reject the standard Kantian idea that all persons can grasp and respond to the ethically relevant facts just by exercising the basic powers of free practical reason that are shared by all normal mature human beings. Unlike Kantians, Aristotelians believe that one must do more than exercise one's will in rational fashion in order to embody sound practical reason or practical knowledge; they argue that we need good moral character and insight to act virtuously and treat others as we should.

\footnotetext{
${ }_{14}$ Of course not all Aristotelians accept this deflationary view of the role that aretaic properties or facts play in the core account of moral motivation. Stohr (2003) e.g. seems to adopt a more robust view.

15 See Hursthouse (2002: chs. 6 and 7).
} 
In section 3, I will say more about how Kantian (rational will) accounts of moral motivation and Aristotelian (insight) accounts affect their conceptions of social morality. For now, I just want to draw attention to the way that adopting an insight account affects Aristotelian thinking about moral responsibility. Roughly put, Aristotelians think that although moral motivation requires more than good willing, people are still rightly held responsible for how well motivated they are and for the ways in which their motivation affects the moral qualities of their acts. ${ }^{16}$ This view would be hard to defend within a legalistic deontic framework because it would imply that people are often morally obligated to others to act (and feel) in ways that they cannot, ${ }^{17}$ but since Aristotelians posit aretaic, rather than legalistic moral facts, they can more easily defend it. They do hold that people may be rightly held responsible for their virtuous and vicious actions even when the aretaic character of their acts was not under their volitional control, but this is not problematic because there is no obvious aretaic analogue to the "obligation entails can" principle. Of course this feature of the Aristotelian view raises deep questions about the sort of responsibility they have in mind when they say we are responsible for acting virtuously or viciously and, although we cannot tackle those questions here, it is worth mentioning that Aristotelian answers often involve reference to a distinction between shame and guilt moralities. Roughly put, Aristotelians are thought to favor a shame morality and the practices of responsibility it involves both because shame, unlike guilt, can legitimately target aspects of people's behavior that are not under their volitional control, and because facts about how virtuous or vicious people are provide reasons of the right kind for harboring attitudes like shame, pride, pity, and disgust, but perhaps not guilt and resentment. ${ }^{18}$

With this broad contrast between Kantian and Aristotelian accounts of moral motivation in mind, we can now flesh out and better describe the social morality objection to virtue ethics. Generally put, the objection is that while virtue ethicists may well be able to account for the

${ }^{16}$ See e.g. Watson (1996).

${ }_{17}$ For a prominent, but I think unpersuasive, attempt to defend this view within a deontic framework, see Scanlon (2000: ch. 6). For a relevant critique, see Wallace (2002: sect. 2).

${ }^{18}$ Morris (1976: 59-63) provides an excellent account of the contrast between guilt and shame moralities. Cf. Williams (2008). 
facts that a well-motivated person cares about others and the common good for their own sake and that moral motivations involve responsiveness to some sort of categorical or authoritative moral reasons, they cannot account for the moral significance of legitimate social expectations and for our being answerable to others for living up to them or not. For the objection to hold water the Kantian must do two things. First, she must say something about the nature of social morality and convince us that it is something we can't reasonably give up. Second, she must argue that virtue ethicists are unable to adequately account for social morality and the expectations it presupposes. I will discuss these in turn.

As the example of carelessly harming your friend suggests, social morality is the domain of morality that involves legitimate ethical expectations to which people can hold one another and social moral motivation involves apt responsiveness to such expectations. This mode of moral motivation can take many forms: for example, it can involve deliberatively recognizing and acting on expectation-based reasons, experiencing expectation-grounded practical necessities, or exhibiting patterns of structured motivation and deliberation that reflect appreciation of others' legitimate expectations. For example, consider Jim, who says he loves his two children very much, but who finds all the time and effort it takes to be their father burdensome and who also regularly complains about it. Hearing his weekly gripes over beer, Jim's unsavory "friend," Sam, seriously suggests that Jim abandon his family and move to another state. Jim is taken aback by this suggestion, and he says abandoning them is out of the question-he could not even consider it. When asked why, he says that he "must" stay with his family, and that he must do so, in part, because his kids would be "totally pissed at him" if he left and because they would "never forgive him." Presumably, if pressed, Jim might say that these reactions would be legitimate and agree that this is because in leaving he would be failing them as a father. This case exemplifies some of the various ways in which a well-motivated agent will be responsive to the expectations of social morality.

In addition, our ordinary practices of holding one another responsible are structured by assumptions about legitimate expectations and the specific people who have the authority to hold us responsible for faring well or ill with respect to them. If Jim were to think about 
leaving his kids and to then do it, for example, they might be rightly upset and resent his lack of commitment to them. Three things are worthy of note here. First, this reaction could be naturally explained and justified by appeal to the idea that in leaving Jim falls short of legitimate expectations that his kids could have for him. Second, while his kids would have warrant to resent what he did to them, other people might well not, and this difference is, again, naturally explained by reference to the fact that the legitimate expectations in question are theirs, not everyone's. Finally, third, the fact that his kids have legitimate expectations that he act differently could also naturally explain why Jim, but not others, should apologize for what he did or make some other attempt to repair or redress his failure, and why Jim's kids, but not others, could rightly demand that he not leave them if they had a chance to talk to him before the fact.

In the interests of space, I am simply going to grant that social morality and social moral motivation of the sort indicated are deep and pervasive aspects of our ordinary lives and relationships and that virtue ethics is in trouble if it is committed to completely eliminating social morality; ${ }^{19}$ we will now turn to questions about whether and how virtue ethicists can make sense of social morality. Following Darwall, I think that an adequate account of social morality must ground both the distinction between legitimate and illegitimate social moral expectations and the authority that people have to hold others to legitimate expectations. For example the account must identify the normative facts that ground the legitimacy of the expectations of Jim's kids that he not leave them and the claim that they, but not just any other people, have warrant to resent his leaving them. To accomplish these tasks, the Kantian will characteristically appeal to the dignity of persons: on the Kantian view, expectations are legitimate just in case they respect the dignity of the persons and our dignity grounds our authority to hold others to our legitimate expectations. In Jim's case his leaving violates a legitimate expectation because in leaving his kids he disrespects their dignity and his kids have special warrant to resent his leaving because it is their dignity that he disrespects.

19 Cf. Darwall's comment about virtue ethics at the bottom of Darwall (2009: 278). 
The problem for virtue ethicists is that they cannot appeal to dignity in the way that Kantians do and it is not clear how the aretaic and teleological normative facts they posit can do the work that dignity does for the Kantians. Moreover, there are three reasons to think that they simply cannot do this work. First of all, as Darwall suggests, it seems that someone could be excellently motivated in response to all the aretaic facts while denying the existence of social morality. Here is what he says, adapted to the case involving Jim:

suppose that we hold an ideal of conduct that excludes [abandoning one's kids] and view this as ignoble, base, or shameful. Unlike agent-neutral reasons to promote good and prevent bad outcomes, this would be an agent-relative reason; it would not be resolvable into any reason to prevent the (agent-neutrally) bad outcome of [children's having been abandoned]. We might hold that it is no less shameful to [abandon one's children] even if this would reduce [child abandonment] overall. But. . . someone might fastidiously avoid [abandoning his children], thinking it base, without thinking that anyone has any authority to claim this of him or hold him accountable. The reason would be conceptually independent of authority and accountability relations..${ }^{20}$

Of course Darwall is picturing someone who intentionally chooses to refrain from doing something because it would be base to do, and neo-Aristotelians might object that on their views good moral motivation does not involve intentionally acting for reasons provided by aretaic facts; but we can reframe Darwall's point to accommodate that fact if we focus on how Jim should evaluate his own motivation and action if and when he does abandon his kids. Specifically, imagine that Jim recognizes that his action and motivation were vicious and base and that he is ashamed of, and regrets, what he did. Moreover, he grants that his kids are rightly chilled by his lack of concern for them and that they may rightly find his vicious behavior deplorable. But imagine, further, that he denies both that anyone had the authority to claim, demand, or expect that he stay and that anyone has the authority to hold him accountable for leaving after the fact. "My virtue is my own concern," he says, "and while others can feel free to judge me on my merits, I do not owe it to anyone else to be more virtuous." This

${ }^{20}$ Darwall (2010: 17). 
would, admittedly, be an odd stance for Jim to take and it is also intuitive to think that a well-motivated agent in Jim's place would agree that his kids could rightly claim, demand, or expect that he stay and hold him accountable for leaving. The problem for the Aristotelian, however, is that, while not living up to this appealing conception of good motivation, Jim seems to be appreciating and aptly responding to all the salient aretaic facts. And if that is right, then it is hard to see how the Aristotelian can provide a normative foundation for the idea that the missing elements are essential aspects of good moral motivation.

One Aristotelian response would be to reject the appearance that Jim could be aptly responding to the vice he instantiates in leaving his kids while denying that anyone had the authority to claim, demand, or expect that he stay or that anyone has the authority to hold him accountable for leaving after the fact. But the problem with this response is that not all instances of vice involve failures to respond to social moral expectations. As Gary Watson points out, for example, someone who chooses a safe but unrewarding option over a risky but potentially rewarding one may exhibit cowardice, but may not be answerable to anyone else for the shortcoming - he may not fall short of anyone else's legitimate expectations. ${ }^{21}$ So even if we grant that aretaic facts can sometimes help warrant legitimate expectations and the authority to hold responsible, the Aristotelian will still owe us an account of why this is sometimes the case and sometimes not; and the Kantian will suspect that this explanation will require the use of legalistic deontic claims about the existence of directed moral obligations, rooted in the dignity of persons.

Finally, third, if the Aristotelian tries to respond to the last point by suggesting that in Watson's case the vicious choice is probably one that does not affect anyone else and that that explains why it does not involve social morality, we can simply note that there are plenty of cases in which someone's vicious behavior does negatively affect another but in which the affected party lacks the authority to hold the vicious person responsible and could not claim, demand, or expect better treatment. This will be true of many cases in which an agent exhibits vice

${ }^{21}$ See e.g. Watson (1996). 
in failing to do an action that a deontologist would classify as supererogatory. For example, a fully virtuous person might generously give his lottery winnings to a friend who is in credit card debt and it might be a bit selfish to instead spend the money on a new car, but the friend could not legitimately claim, demand, or expect the gift or, with warrant, hold his friend responsible for being less than ideally generous (if he opted for getting himself the car instead). Moreover, there are cases in which two people are affected in a similarly negative way by similarly vicious behavior, but in which only one has legitimate expectations let down and has the authority to hold the vicious person responsible. For example it would be miserly to hoard my money and refuse to lend it to a stranger or to my own kids when they each could get much more out of using the money than I would, but while my kids might legitimately expect me to loan them money in some such circumstance (e.g. to go to college) and hold me accountable for failing to do so, the same cannot be said of the stranger. He might disapprove of my lack of generosity and even hold it against me, so to speak, but he cannot claim I have done him wrong, and fallen short of his legitimate expectations, in refusing to give him a loan.

Given these points, we can reasonably conclude that Aristotelians need to posit some additional moral reasons or facts, over and above plain aretaic ones, in order to give an account of social morality; they need to identify some further normative facts which can explain why vicious behavior is rightly thought to violate legitimate expectations in some cases and not others and why some people have the authority to hold others responsible for such violations and others do not. This is the challenge that lies at the heart of the social morality objection to virtue ethicists, and, while I don't think virtue ethicists have adequately addressed it as of yet, I also have a proposal for how they can do so: my basic suggestion is that virtue ethicists should admit that moral motivation involves responsiveness to two sorts of distinctively moral factsaretaic ones and social moral ones-and then give a non-legalistic account of the social moral ones. To see how to accomplish the later task, consider the idea that our legitimate expectations and our authority to hold people responsible for how they fare relative to them are both best understood by reference to the normative standards that govern our interpersonal relationships. Your friend can resent your lack of concern for his well-being because in manifesting that lack of concern you 
are bad friend to him, and Jim's kids can resent his abandoning them because in doing so he is a bad father to them. To develop that suggestion further, we would need to provide an account of various relationships, their entrance and exit conditions, the norms of relating in good and bad ways, and of the ways in which people in the relevant relationships can aptly hold one another responsible for how they fare relative to those norms. In this chapter, my main concern is to articulate and face the social morality objection and to identify some of the main things that would divide virtue ethical and neo-Kantian accounts of social morality, so I am not going to get into any of the details that would be required to develop a specific virtue ethical account of social morality and the relationship norms it involves. Instead, I want to say a bit more about structure of my proposed virtue ethical account and then discuss Darwall's argument that social morality is implicitly deontic.

I just suggested that a virtue ethical account of social morality could be grounded in an account of relationship norms such as norms for good fatherhood and good friendship, but for this account to work, it must explain why vicious behavior is rightly thought to violate legitimate expectations in some cases and not others and why some people have the authority to hold others responsible for such violations and others do not; and it must do those things without invoking legalistic deontic normative facts. A neo-Kantian might grant, for example, that your son (but not a stranger) can legitimately expect you to loan him money just in case, and because, you would be failing him (but not a stranger) as a father if you refused to give him the loan, but he might also insist that the relevant norm of good fatherhood is best understood in legalistic deontic terms. For example, he might suggest that to be a good father, one is morally obligated to respect the moral dignity of one's children-for example, by respecting their autonomy rights. In response to this challenge, I need to provide an alternative account of relationship norms that does not rely on such legalistic notions. My general suggestion is that we can do this by holding that norms for good and bad fatherhood, friendship, etc. should be understood by appeal to an account of virtuous agency and the ends that a virtuous person would endorse. Specifically, I suggest that when someone fulfills various interpersonal roles well (being an excellent friend, parent, etc.) their success and the standards to which they live up should be explained by appeal to the virtue they instantiate and the fact that they 


\section{Virtue Ethics and Social Morality}

have adopted and internalized the ends that a virtuous person in such a relationship would pursue because he or she was in that relationship. ${ }^{22}$ For example, whether or not you live up to your son's legitimate expectations in giving him a loan or not depends on the virtue or vice your action instantiates and on the extent to which you have adopted and internalized the ends that a virtuous person would have because they were a parent.

The virtue ethical account of relationship norms just mentioned suggests that you have the authority to hold someone responsible for falling short of a legitimate expectation just in case (i) you are in a substantive relationship with them, (ii) they exhibited some vice in relating to you, and (iii) their exhibiting that vice is indicative of their failure to fully adopt and internalize an end that a virtuous person would have if (and because) she were in a relationship of the relevant sort. Now as with the basic account of social morality introduced before, there are lots of questions one would need to answer to fill out this scheme for a virtue ethical account, but I think it gives us reason to think that virtue ethicists can give a coherent account of social morality without using deontic concepts or claims and that they can therefore rebuff the social morality objection. ${ }^{23}$

22 More specific claims about specific relationships will, no doubt, be subject to debate and the relevant relationship norms will often be partially dependent on contextual factors (cultural, economic, etc.) — the ends that a virtuous person would adopt because of the relationships she is in might well vary depending on contextual factors. I think this makes the approach appealingly flexible, not objectionably relativistic.

${ }^{23}$ Let me say something about why I don't think Annas (this volume) provides an adequate alternative to this account. Her basic idea is that duties are rooted in institutional roles, and I don't think she develops it in a way that can address the social morality objection. First, not all institutional duties are directed duties, owed to specific other persons, and not all of them are ones to which others can hold us accountable, so to account for the demands of social morality Annas needs to provide an account of which institutional duties fit these conditions and why. I worry she misses this point when working to identify the sort of demandingness that deontologists think virtue ethics is missing. Second, Annas suggests that it is characteristic of institutional duties that agents do not need to exercise their powers of practical reasoning to figure out their content—she says the content is "prespecified" by the relevant role or institution. This may be true of many institutional duties, but it is not a feature of social moral norms such as norms of good friendship or parenthood. As I emphasize in section 3, we often need insight or wisdom to figure out how to be a good friend or parent to another. And since social moral expectations and practices of accountability extend to cases in which people fall short of such norms, it is hard to see how Annas' account of duties could ground a satisfying account of social morality and its demands. 
Of course, the virtue ethical account of social morality just sketched will probably not satisfy Kantians who think that social morality extends to the relations between any persons. They hold that just because you are a person you can reasonably expect others to respect your moral dignity, and that complete strangers (or even rational aliens) can reasonably expect you to treat them as ends in themselves. The account just sketched will not vindicate this expansive conception of social moral expectations. But for the social morality objection to gain purchase against virtue ethicists, it cannot rest on the assumption that social morality, and the legitimate expectations it involves, is universal in that way. Virtue ethicists have long questioned the need to posit universal obligations grounded in the dignity of persons and pointed out that we have compelling aretaic reasons to treating far-flung strangers well; and even if one finds this view counterintuitive, one would be hard pressed to argue it is irrational, incoherent, or practically untenable. ${ }^{24}$ To provide a solid challenge to virtue ethicists, then, the social morality objection must rest on the claim that virtue ethicists cannot account for social morality as it is manifest in ordinary human lives and relationships of the sort that we all value and can't imagine living without, not in the claim that a virtue ethical account of social morality will not have the scope that some find intuitively appealing.

To clarify this point, consider a modified version of Singer's case of someone drowning in a nearby pond. In the original case, the person is not someone to whom you are personally related, but let's begin by assuming it is your son who is drowning. Now regardless of which account of moral motivation we adopt, we can agree that a morally motivated person will try to save his child and be moved by the facts that it would be bad for the person to die and that his death would be useless. As Scanlon (1982) famously points out, however, Kantians will typically draw attention to the further facts that your drowning child has an inherent dignity and that to respect him, you must save him. In the light of Darwall's recent work, the Kantian would probably also add that those deontic facts give you second-personal or social moral reasons to save your child. ${ }^{25}$ Because they reject the legalistic deontic claims that ground this Kantian view, Aristotelians will typically

${ }^{24}$ For a recent discussion, see Hursthouse (2007).

25 See my explanation of Darwall's terminology in the next section. 
adopt a different approach. Now standard neo-Aristotelians can claim that the person who fails to help not only fails to act on compelling reasons but also exhibits heartlessness, cruelty, or some other vice; but, as we have seen, this does not accommodate the further social moral claim that in letting your son drown you fall short of a legitimate social moral expectation. So to do better, I think Aristotelians should adopt and develop my proposed social-moral virtue ethical view in order to explain why you should be responsive to such expectations; you should save your son because doing so would be compassionate but also because he can reasonably expect you to save him, given that you are his father.

In other cases, such as the original Singer one, my proposed social-moral virtue ethical account may diverge from Kantian accounts and some people's idea of common sense. Assuming the relevant case involves an utter stranger who is drowning, my account might well dovetail with the standard Aristotelian one, and imply that you should help the person because that will prevent a senseless death, and because if you fail to help you will exhibit vice- but it will stop short of positing social moral expectations for you to help. In practical terms, one upshot here will be reflected in the kinds of warranted things that the victim could say to you if you refused to help. Roughly speaking, your child may tell you that you must save her on the ground that you owe it to her as a parent, while the stranger cannot make an analogous claim and should, instead, say things like, 'How can you pretend that saving me is less important than keeping your feet dry?', 'What are you, some kind of moral monster?', and 'How will you be able to look at yourself in the mirror after this?'

I admit that this result may strike some as counterintuitive because they think they may demand and "extract" respect for their dignity from strangers. People who hold this view may prefer, and hope to give compelling reasons to prefer, an account of social morality that accommodates that intuition, and that is a response I welcome. My aim here is to rebuff the social morality objection, which would have us reject non-deontic virtue theories because they are in principle unable to account for social morality, understood as an essential aspect of ordinary lives and relationships. Having established that this objection fails I would welcome debate about what type of account of social morality we should prefer and why. 


\section{DEFENDING THE SOLUTION'S COHERENCE}

In the first two sections of this chapter I introduced the social morality objection to virtue ethics and sketched an approach to rebuffing it. To further defend the coherence of this approach and highlight the differences between virtue ethical and neo-Kantian accounts of social morality, I now turn to Stephen Darwall's book, The Second Person Standpoint. In it, Darwall contends that only legalistic deontic accounts of social morality are tenable-in short, he argues that if we recognize the value of social morality in personal relationships and ordinary life, then we are committed to endorsing modern moral deontic views about the equal dignity of persons and about our being obligated to treat all persons only in ways that they could not reasonably reject. One target of this argument is the moral skeptic, but another is the virtue ethicist who suggests that we abandon legalistic deontic morality. Now unlike Korsgaard, for example, Darwall does not aim to show that it would be practically irrational or volitionally incoherent for anyone to adopt skepticism or a virtue ethical view, but he does argue that these views commit their adherents to completely rejecting social morality and, by extension, the aspects of ordinary life that depend on it. Darwall reasonably suspects this will make these views unpalatable to most of us, and he suggests that it is psychologically unrealistic to think that an ordinary human being could abandon her tacit commitment to legalistic deontic morality and fully adopt moral skepticism or virtue ethics. ${ }^{26}$

If Darwall's arguments are sound, my proposed solution to the social morality objection is bankrupt. I sketched a virtue ethical account of social morality and claimed it would be developed without the use of legalistic deontic concepts, but if Darwall is right then that claim cannot be sustained; he provides an analysis of social morality which purports to show that it involves commitment to the equal moral dignity of persons. Thankfully, I do not think that his analysis is compelling or that it threatens the coherence of my proposed solution. However, before providing grounds for that assessment, let me say something about his terminology and the overall argument of his book.

Throughout his book, Darwall uses phrases such as 'second personal reasons', 'second personal address', and 'the second personal standpoint'.

26 Darwall (2009: 278). 
In the terms I have been using in this chapter, second-personal reasons are ones grounded in facts about the legitimate expectations to which others have the authority to hold you, second-personal address is address by means of which another expresses to you that she has legitimate expectations about how you treat her and that you are answerable to her for living up to those expectations, and the second-personal standpoint is the standpoint we inhabit when we recognize second-personal reasons, act in ways that presuppose the existence of second-personal reasons, etc. ${ }^{27}$ Now Darwall begins his book with a series of rich and nuanced arguments about how defenders of deontology should build their theories of moral obligation-he gives a second-personal account of moral obligation and argues that deontologists must accept it over various utilitarian, intuitionistic, and neo-Kantian accounts. His arguments for these claims are interesting, but since I am interested in his further argument about the coherence of non-legalistic accounts of social morality, I will skip over them and focus on chapter 10, which contains Darwall's analysis of second-personal address. This analysis is explicitly supposed to capture the presuppositions that we make when participating in ordinary life and relationships-it is supposed to uncover the (deontic) presuppositions we make when we participate in social morality of the sort that even virtue ethicists should aim to accommodate, and it is not supposed to depend on any antecedent legalistic assumptions about morality or moral motivation.

To grasp the core features of Darwall's analysis, we can think about how it would apply to the example of tempted Jim, who considers abandoning his kids and family. In describing that case I said that Jim's kids might have warrant to demand that he stay, and this is the kind of case of second-personal address on which Darwall focuses. He makes three main claims about what demanding social moral address presupposes. First, that in addressing someone in order to convey your expectations and the fact that they are answerable to you for living up to them, you presuppose that the person is capable of taking responsibility for how they fare relative to those expectations and for complying with those expectations. Second, if and when the other person takes responsibility for how she fares relative to the relevant expectations and complies, she

${ }^{27}$ I will stick with my own terminology but I nothing about my argument should hinge on this. 
can usefully be thought of as sharing the standpoint you would adopt if you were to hold her responsible for how she fares and as appreciating the grounds that legitimate the expectations to which she is being held. Finally, third, when addressing someone second-personally, you presuppose that the other person can adopt your standpoint, appreciate the grounds that legitimate your expectations, and comply with those expectations by exercising the basic powers of free rational agency that you share with all other persons.

The third claim, about appreciation and compliance being accessible to those who exercise their basic powers of free rational agency well, is key for Darwall's larger argument. On the basis of it, he argues that a legitimate demand (to meet a legitimate expectation) is distinguished from mere coercive force by the fact that in making a legitimate demand one respects the target of one's demand as a free and rational person. He then adds that if you respect the other as a free and rational person you presuppose that the other has the authority to address legitimate demands to you too, and that in presupposing such shared authority you commit yourself to the "common basic dignity of persons." ${ }^{28}$ Of course there are various steps in this overall argument that one might question, but I want to focus on the initial claims about rational appreciation and compliance. In short, I think we should reject these claims as claims about the demanding expectations that are embedded in social morality; by reflecting on cases we can see that participation in social morality, as it shows up in ordinary relationships and life, does not commit us to thinking that people can appreciate the ground of, and comply with, demanding ethical expectations just by exercising their basic free and rational powers. On the contrary, people often need skill or insight to appreciate and comply with demanding legitimate expectations.

Now Darwall starts out from the plausible thought that in demanding that someone live up to a legitimate expectation, we ordinarily presuppose that we are not just coercing the person and that, therefore, they could respond to our demand by rationally and voluntarily complying. But Darwall goes further and maintains that when the target rationally and voluntarily complies he or she does so just by exercising

28 Darwall (2009: 271-7). 
her basic free and rational powers. To see that this further claim is false, we need only bring to mind cases in which the target is able to appreciate the expectation's ground or comply with the expectation only because she has some non-basic skill or insight (i.e. some kind of virtue that persons contingently enjoy).

For an example in which one needs skill, and not just good will, to comply, consider Darwall's case of Barbara Fusar Poli. Poli is an Italian ice dancer who famously "stared down" her partner Maurizio Margaglio after he dropped her during Olympic competition. Darwall holds that, in staring down her partner, Poli held Margaglio responsible for falling short of her legitimate expectations and that this case therefore involves addressing second-personal reasons. ${ }^{29}$ But since dropping her was presumably a failure of skill, not mere will, this is a case in which the target of a legitimate expectation could not live up to that expectation by the mere exercise of the basic powers he shares with all other free and rational persons; and it shows that sometimes we can legitimately hold people accountable for failures to live up to expectations that they need non-basic skills, powers, or virtues to fulfill. ${ }^{30}$

The ice-skater case shows that it might take non-basic skill to comply with a demanding social moral expectation, but there are other cases that show it might require some non-basic cognitive powers (what I am calling insight). Take Ralph, a man who emotionally neglects his wife and kids. He agrees that he should be a good father and husband but he does not understand that that requires his giving them emotional support-perhaps he even denies that. Of course we might naturally also imagine Ralph as someone with character flaws that would prevent him from doing what he should if he knew what it was, but we need not assume that to be the case; his failure to understand the importance of being there emotionally for those one loves could be purely cognitive. The point I want to make about Darwall's analysis in this context is that, if we think of someone else, who has the insight that Ralph lacks, and consider a case in which someone demands emotional support from that person (with insight), we can see that the person will be able

29 Darwall (2009: 42 n. 5).

${ }^{30}$ Of course Darwall might point out that in some cases the defect in skill was the avoidable result of previous failures to will well, but I am assuming this is not true in all relevant cases. 
to voluntarily and rationally comply only because he enjoys a form of cognitive insight into what being a good parent and partner involvesa form of insight not available to just any agent who exercises her basic powers of free rational agency.

Generalizing, we can say that in order to form true beliefs about what others can legitimately expect of us and why, to figure out what we need to do to meet those expectations, and to then live up to them, we often need to make use of insights and skills that go above and beyond the basic free rational powers all normal persons possess. So while Darwall is right to think that when we demand that someone comply with our expectations we presuppose they can rationally and voluntarily comply with those demands, their ability to do so might rest on the fact that they enjoy various virtues that not all mature persons enjoy. So Darwall's proposed analysis simply does not fit ordinary cases of second-personal demanding address in the way he claims, and he cannot use that analysis to ground his claim that legitimate demands or expectations are legitimate only if they respect the dignity of persons; on the contrary, reflection on ordinary cases shows that demanding social moral address is often legitimate and non-coercive only if it respects the degree of virtue of the addressee.

Of course this discussion of Darwall's book is far from complete and conclusive, and there are other strands of his rich project that would need to be addressed to make a compelling case for the virtue ethical account of social morality I have sketched; but if my reconstruction and assessment of Darwall's analysis of legitimate demanding social address is correct, then I have at least identified a plausible virtue ethical strategy for defanging one of his central arguments against non-legalistic accounts like mine.

In conclusion, I want to briefly return to the larger question of the ways in which a virtue ethical account of social morality will differ from Kantian ones. Insofar as Kantians base their account of social morality on respect for the inherent dignity of persons, they will tend to claim that any person with basic free and rational powers can hold others to certain moral expectations and that the expectations to which we can be held must be ones that people can appreciate and comply with by the use of those basic powers. A virtue ethical view will encourage us to reject both of these claims. First, as noted earlier, a virtue ethical view that appeals to virtue-based substantive relationship norms, instead of 


\section{Virtue Ethics and Social Morality}

dignity, will probably not justify a social morality with universal scope. Second, we can now note that a virtue ethical view will encourage us to reject the Kantian restriction on what we can legitimately expect of one another; adoption of a virtue ethical account will encourage us to reject Kantian claims about social morality being constituted by a set of publicly accessible expectations. ${ }^{31}$ Instead, the virtue ethical view would have us believe that to grasp and live up to legitimate ethical expectations, of the sort that structure our ordinary lives and relationships, we may need to develop skill and insight of a sort that goes beyond what we can achieve through the use of our basic free and rational powers. In this chapter I have not, of course, developed such a view in any detail or given compelling reasons for thinking we should prefer it over Kantian ones, but I hope I have motivated an interest in tackling those tasks by showing how virtue ethicists can hope to provide a coherent account of social morality that can compete with Kantian ones. ${ }^{32}$

\section{REFERENCES}

Anscombe, Elizabeth. 1958. "Modern Moral Philosophy,” Philosophy, 33/124: 1-19.

Annas, Julia. 2008. "Virtue Ethics and the Charge of Egoism," in Morality and Self-Interest (Oxford: Oxford University Press).

Crisp, Roger. 2014. "Superoregation and Virtue," in M. Timmons (ed.), Oxford Studies in Normative Ethics (Oxford: Oxford University Press), iii. 13-34.

Darwall, Stephen. 2009. The Second-Person Standpoint (Cambridge, MA: Harvard University Press).

Darwall, Stephen. 2010. "Precis: The Second-Person Standpoint," Philosophy and Phenomenological Research, 81/1: 216-28.

Foot, Philippa. 1972. "Morality as a System of Hypothetical Imperatives," Philosophical Review, 81/3: 305-16.

31 See e.g. Darwall (2009: 313-14): “The right's connection to mutual accountability also explains why it essentially involves publicly articulable principles in a way that other ethical standards, such as ideals of virtue, need not. Standards of right and wrong are, in their nature, bases for public expectations, for what we justifiably expect of one another. So they must be able to be publicly articulated and accessible. It would be unreasonable to hold people accountable to standards whose application required some special sensibility ordinary moral agents could not be assumed to have or that could not be formulated in ways that ordinary agents can understand. In this way, standards of moral right are a moral 'law,' modeled on law as we generally understand it." Given the virtue ethical view of social morality I have sketched, Darwall's claims about reasonable accountability are wrongheaded.

32 Thanks to Paul Hurley, Brad Hooker, Shelly Kagan, Ben Yelle, Richard Kraut, David Shoemaker, Matthew Hanser, Earl Conee, John Deigh, Adam Kadlac, Mark Timmons, two anonymous reviewers for OUP, and, especially, Sarah Stroud. Research for this article was generously supported by a Character Project Grant, funded by the Templeton Foundation. 
Hurka, Thomas. 2012. "Aristotle on Virtue: Wrong, Wrong and Wrong," in J. Peters (ed.), Aristotelian Ethics in Contemporary Perspective (New York: Routledge), 9-26.

Hursthouse, Rosalind. 2002. On Virtue Ethics (New York: Oxford University Press).

Hursthouse, Rosalind. 2007. "Human Dignity and Charity," in Jeff Malpas and Norelle Lickless (eds), Perspectices on Human Dignity: A Conversation (Dordrecht: Springer), 59-72.

Irwin, T. H. 1992. "Eminent Victorians and Greek Ethics: Sidgwick, Green, and Aristotle." In Essays on Henry Sidgwick (Cambridge: Cambridge University Press). 279-310.

Kant, Immanuel. 1997. Critique of Practical Reason, ed. Mary J. Gregor (Cambridge: Cambridge University Press).

Larmore, Charles. 1990. “The Right and the Good,” Philosophia, 20/1-2 (July): 15-32.

Lebar, Mark. 2005. “Three Dogmas of Response-Dependence,” Philosophical Studies, 123/3 (Apr. 2005): 175-211.

McDowell, John. 1978. "Are Moral Requirements Hypothetical Imperatives?” Proceedings of the Aristotelian Society, supplementary vol. 52 (1 Jan.): 13-42.

Morris, Herbert. 1976. On Guilt and Innocence: Essays in Legal Philosophy and Moral Psychology (Berkeley-Los Angeles: University of California Press).

Pettigrove, Glen. 2011. "Is Virtue Ethics Self-Effacing?” Journal of Ethics, 15/3: 191-207.

Scanlon, T. M. 1982. "Contractualism and Utilitarianism," in A. Sen and B. Williams (eds), Utilitarianism and Beyond (Cambridge: Cambridge University Press), 103-28.

Scanlon, T. M. 2000. What We Owe to Each Other (Cambridge, MA: Harvard University Press).

Stohr, Karen E. 2003. "Moral Cacophony: When Continence is a Virtue," Journal of Ethics, 7/4: 339-63.

Strawson, P. F. 1961. “Social Morality and Individual Ideal,” Philosophy, 36/136 (Jan.): 1-17.

Toner, Christopher. 2006. "The Self-Centredness Objection to Virtue Ethics," Philosophy, 81/4: 595-618.

Wallace, R. Jay. N.d. “The Deontic Structure of Morality” (MS—available on his website).

Wallace, R. Jay. 2002. “Scanlon's Contractualism,” Ethics, 112/3 (Apr.): 429-70.

Watson, Gary. 1996. “Two Faces of Responsibility,” Philosophical Topics, 24: 231.

Wiggins, David. 1991. "Categorical Requirements: Kant and Hume on the Idea of Duty," The Monist, 74/1: 83-106.

Williams, Bernard. 1985. Ethics and the Limits of Philosophy (Cambridge, MA: Harvard University Press).

Williams, Bernard. 2008. Shame and Necessity, 2nd edn (Berkeley-Los Angeles: University of California Press). 